\title{
Pemberdayaan Guru dalam Literasi untuk Meningkatkan Kemampuan Berpikir Kritis Siswa
}

\author{
Harlinda Syofyan ${ }^{1 *}$, Ratnawati Susanto ${ }^{2}$, Yeni Duriana Wijaya ${ }^{3}$, Vebryanti ${ }^{4}$, Melinda $^{2}$ \\ Tesaniloka P5
}

1,2,3,4,5Universitas Esa Unggul

\section{A R T I C L E I N F O}

Article history:

Received 20 May 2019

Received in revised form 10 June 2019

Accepted 30 July 2019

Available online 30 August 2019

Kata Kunci:

Pemberdayaan, guru,

literasi, berpikir kritis

Keywords:

Empowerment, teacher,

literacy, critical thinking

\begin{abstract}
A B S T R A K
Program Kemitraan Masyarakat (PKM) ini bertujuan untuk memberdayakan guru dalam kegiatan literasi di sekolah sebagai pelopor sekaligus sebagai pelopor untuk mengarahkan siswa dalam membentuk cara berpikir siswa agar lebih kritis dalam pembelajaran. Oleh karena guru memiliki peran sentral dalam pembelajaran di kelas. Maka guru diharapkan memiliki pengetahuan yang luas sehingga materi yang disampaikan menjadi lebih menarik dan dimengerti oleh siswanya. Metode yang digunakan dalam kegiatan ini adalah metode partisipatif melalui tiga tahap yaitu 1) sosialisasi, (2) pendampingan, 3) monitoring dan evaluasi. Hasil dari pelaksanaan adalah; 1) pemahaman tentang literasi sains meningkat yang terlihat dalam aspek kompetensi dan indicator sebesar $43 \%$, pengorganisaisan materi ajar 54\%, dalam penggunaan strategi sebesar $65 \%$ dan peningkatan literasi sains $50 \%$. Antusiasme peserta juga baik dengan rata-rata kehadiran $84 \%$, sementara hasil monitoring kemampuan berpikir kristis siswa juga meningkat sebesar $65 \%$. Untuk itu diharapkan kegiatan literasi ini perlu dilaksanakan secara berkelanjutan agar proses belajar mengajar berjalan sesuai yang diharapkan.
\end{abstract}

\section{A B S T R A C T}

Program Kemitraan Masyarakat (PKM) aimed to empower teachers in literacy activities in schools as pioneers as well as pioneers to direct students in develop students' ways of thinking to be more critical in learning. Because the teacher has a central role in learning in the classroom. Then the teacher expected to have extensive knowledge so that the material presented becomes more interesting and understood by the students. The method used in this activity is a participatory method through three stages, namely 1) socialization, (2) mentoring, 3) monitoring and evaluation. The results of the implementation are; 1) understanding of scientific literacy increased as seen in the aspects of competence and indicators by $43 \%$, organizing teaching materials $54 \%$, in the use of strategies by $65 \%$ and increasing scientific literacy by $50 \%$. The enthusiasm of participants was also good with an average attendance of $84 \%$, while the results of monitoring students' critical thinking skills also increased by $65 \%$. For this reason, it is hoped that literacy activities will need to be carried out continuously so that the teaching and learning process runs as expected.

\footnotetext{
* Corresponding author.

E-mail addresses: HarlindaSyofyan1@gmail.com (Harlinda Syofyan)
} 


\section{Pendahuluan}

Literasi merupakan istilah yang sering digunakan seseorang untuk merujuk kepada kemampuan diri individu dalam kegiatan membaca, menulis, berbicara, menghitung dan memecahkan masalah sesuai tingkat keahliannya masing-masing. Literasi juga dihubungkan kepada seberapa luas wawasan seseorang dalam menguasai bidang ilmu dan keahliannya. Berbagai jenis literasi saat ini sedang ramai dibicarakan orang dalam dunia bisnis maupun pendidikan, diantaranya ada istilah literasi kesehatan, literasi finasial, literasi digital, literasi data, litersai kritikal, litersai visual, literasi teknologi, literasi statistik, literasi informasi, dan lain sebagainya. Literasi menjadi kunci manusia dalam berproses menjadi manusia yang lebih berpengetahuan dan mendukung peradaban (Purwaningtyas, 2018), (Ibda \& Rahmadi, 2018).

Gerakan literasi yang dicanangkan oleh pemerintah merupakan kunci awal untuk menuju kemajuan dimana masyarakat melek dengan keahlian mereka masing-masing dengan kegiatan membaca. Karena dari kegiatan ini kualitas hidup dan intelektual seseorang bisa dilihat, apalagi kemampuan literasi meningkat maka kualitas hidup seseorang juga akan meningkat. Beberapa tujuan dicanangkan literasi antara lain, dapat membantu meningkatkan pengetahuan masyarakat dengan membaca informasi, dapat meningkatkan kemampuan seseorang dalam berpendapat secara kritis terhadap suatu karya, dapat menumbuhkan dan mengembangkan prilaku luhur di dalam diri seseorang, dapat meningkatkan nilai kepribadian melalui kegiatan membaca dan menulis, dapat menumbuhkan dan mengembangkan budaya literasi ditengah masyarakat serta membantu meningkatkan kulaitas penggunaan waktu seseorang agar lebih bermanfaat (Jufri, Ramdani, Gunawan, Bachtiar, \& Wildan, 2018), (Situmorang, 2016).

Ada beberapa cara meningkatkan literasi seseorang, salah satunya yang ditempuh adalah dengan rajin membaca buku. Namun keadaan itu ternyata masih rendah dilakukan di negara kita, karena masih banyak siswa sekolah memiliki tingkat pengetahuan rendah dan terkadang hanya mengharapkan atau menampung informasi yang diberikan oleh guru di sekolah. Ada beberapa hal yang menyebabkan kondisi ini terjadi diantaranya, guru memiliki minat baca yang rendah, buku-buku yang menarik dan mendukung ilmu pengetahuan sulit untuk diakses, kondisi perpustakaan yang terbengkalai dan kurang memadai, minimnya buku bacaan yang tersedia, kemudian karena kemampuan guru dalam menerapkan pembelajaran yang berbasis literasi masih rendah (Nurdin, 2019), (Kharizmi, 2015).

Guru memiliki peran sentral dalam pembelajaran di dalam kelas. Karena apa yang diinstruksikan guru biasanya akan dijalankan oleh siswanya. Guru sebagai teladan dan arsitek sekaligus sutradara di dalam kelasnya masing-masing. Untuk mampu menjadi arsitek pembelajaran, maka guru harus belajar merancang pembelajaran yang asyik, dan menyenangkan. Guru senang, dan peserta didikpun senang dan menyimak setiap pembelajaran yang dirancang oleh guru. Guru yang tidak merancang pembelajarannya dengan baik maka pembelajarannya pasti tidak akan terarah Dan tentu saja pembelajaran yang sperti ini pasti tidak menarik apalagi menyenagkan bagi siswanya (Nuri Ramadhan, 2017), (Hasyim, 2014).

Guru sebagai teladan dan arsitek sekaligus sutradara di dalam kelasnya masing-masing. Untuk mampu menjadi arsitek pembelajaran, maka guru harus belajar merancang pembelajaran yang asyik, dan menyenangkan. Guru senang, dan peserta didikpun senang dan menyimak setiap pembelajaran yang dirancang oleh guru. Guru yang tidak merancang pembelajarannya dengan baik maka pembelajarannya pasti tidak akan terarah Dan tentu saja pembelajaran yang sperti ini pasti tidak menarik apalagi menyenangkan bagi siswanya. Guru yang merancang pembelajaran dan menarik membawakan materi di dalam pembelajaran adalah guru yang memiliki wawasan yang luas. Hal ini tidak terlepas dari minat baca guru tentunya, yang disebut sekarang sebagai budaya Literasi, yang dapat diartikan sebagai budaya membaca dan menulis. Sehingga dalam kegiatan program literasi sekolah guru dijadikan sebagai agen perubahan yang bertanggungjawab mengarahkan dan membentuk perilaku dan pola brpikir siswa menjadi lebih baik (Kurnianingsih, I., Rosini, dan Ismayati, 2017), (Rosdiana, Nurita, \& Sabtiawan, 2018), (H. Syofyan \& Ismail, 2018).

Dalam hal ini pertama, Guru sebagai perancang pembelajaran maka dituntut untuk menarik membawakan materi di dalam pembelajaran adalah guru yang memiliki wawasan yang luas. Hal ini tidak terlepas dari minat baca guru tentunya, yang disebut sekarang sebagai budaya Literasi, yang dapat diartikan sebagai budaya membaca dan menulis. Sehingga dalam kegiatan program literasi sekolah guru dijadikan sebagai agen perubahan yang bertanggungjawab mengarahkan dan membentuk perilaku dan pola berpikir siswa menjadi lebih baik. Dalam kaitannya kegiatan literasi guru adalah sebagai fasilitator sekaligus subjek dan memiliki fungsi-fungsi yang sangat penting dalam proses pembelajaran. (Ismail, 2010), (Seknun, 2012), (H. H. A. Syofyan, 2016).

Kedua guru sebagai pengelola pengajaran harus memiliki kemampuan mengelola seluruh proses kegiatan belajar mengajar dengan menciptakan kondisi-kondisi belajar yang menarik. Ketiga guru sebagai evaluator dalam pembelajaran sehingga mampu mendiagnosis kelemahan siswa di dalam kelas, dan mampu memperbaiki pembelajarannya. Misalnya dengan memberikan motivasi kepada siswa untuk 
menambah pengetahuan dengan pembiasaan sejak dini budaya membaca agar menanbah minat mereka dalam ilmu pengetahuan yang semakin maju (Ardy, 2018), (H. Syofyan, MS, \& Sumantri, 2019).

Kondisi awal di sekolah mitra PKM sudah mulai menerapkan literasi 15 menit sebelum masuk kelas, namun kurang konsisten. Apalagi guru sebagai narasumber dalam pembelajaran juga harus konsistem meliterasi diri mereka sendiri. Berangkat dari situasi di atas maka kami dari TIM PKM bermaksud untuk memberdayakan guru sebagai pelopor meliterasi diri untuk menumbuhkan kebisaaan membaca bagi siswanya sehingga mengarahkan siswa agar memiliki kemampuan dalam berpikir kritis.

\section{Metode}

Sasaran kegiatan Program Kemitraan Masyarakat ini adalah guru-guru di SDN Jelambar Baru 01 Jakarta Barat sebanyak 19 orang. Metode kegiatan yang dilakukan Program Kemitraan Masyarakat ini adalah dengan metode partisipatif, artinya mitra secara aktif dilibatkan dalam semua tahapan kegiatan. Kegiatan ini menggunakan metode ceramah, praktek, serta evaluasi dari implementasi materi yang diberikan. Sehingga akan tergambar peningkatan yang dari hasil yang diharapkan yang dapat dijadikan sebagai acuan untuk melaksanakan kegiatan literasi di sekolah mitra.

Sarana dan alat yang digunakan adalah materi pelatihan, LCD, rol kabel, pengeras suara dan kertas HVS. Rancangan evaluasi dari kegiatan ini ditekankan pada proses dan hasil, dimana guru-guru dilatih dulu melalui games dan simulasi pada saat pelatihan, kemudian dilanjutkan dengan implementasi pada rancangan pembelajaran mereka masing-masing, dan pada saat melaksanakan pembelajaran di kelas. Kemudian dilanjutkan untuk melihat perkembangan siswa dalam pembelajaran.

\section{Hasil dan pembahasan}

Berdasarkan hasil pelaksanaan program kemitraan masyarakat ini yang berlangsung dari April sampai bulan Agustus 2019, hasil evaluasi dari kegiatan yakni berupa implementasi literasi dalam pembelajaran di kelas didapatkan hasil seperti tabel di bawah ini.

Tabel 1. Implementasi Literasi Sains

\begin{tabular}{|c|c|c|c|c|c|c|c|c|c|c|}
\hline \multirow{3}{*}{ SEKOLAH MITRA } & \multirow{3}{*}{$\begin{array}{c}\text { JUML } \\
\text { AH } \\
\text { PESE } \\
\text { RTA }\end{array}$} & \multicolumn{9}{|c|}{$\begin{array}{l}\text { PENILAIAN IMPLEMENTASI LITERASI SAINS DALAM PEMBELAJARAN } \\
\text { INKUIRI }\end{array}$} \\
\hline & & \multicolumn{3}{|c|}{$\begin{array}{l}\text { Keterampilan Membuka } \\
\text { Pembelajaran }\end{array}$} & \multicolumn{3}{|c|}{$\begin{array}{c}\text { Keterampilan } \\
\text { Kegiatan Inti }\end{array}$} & \multicolumn{3}{|c|}{$\begin{array}{l}\text { Keterampilan Menutup } \\
\text { Pelajaran }\end{array}$} \\
\hline & & $\mathrm{B}$ & $\mathrm{C}$ & $\mathrm{K}$ & B & $\mathrm{C}$ & $\mathrm{K}$ & B & $\mathrm{C}$ & $\mathrm{K}$ \\
\hline $\begin{array}{l}\text { SDN Jelambar } \\
\text { Baru 01 Pagi }\end{array}$ & 16 & & & & & & & & & \\
\hline Profil Awal & & 5 & 7 & 4 & 4 & 7 & 4 & 3 & 7 & 5 \\
\hline Profil Akhir & & 10 & 5 & 1 & 9 & 4 & 1 & 12 & 2 & 2 \\
\hline Peningkatan & & 5 & 2 & 3 & 3 & 5 & 3 & 9 & 5 & 3 \\
\hline$\%$ Peningkatan & & $100 \%$ & $29 \%$ & $75 \%$ & $75 \%$ & $71 \%$ & $75 \%$ & $300 \%$ & $71 \%$ & $60 \%$ \\
\hline Program & 16 & & & & & & & & & \\
\hline
\end{tabular}

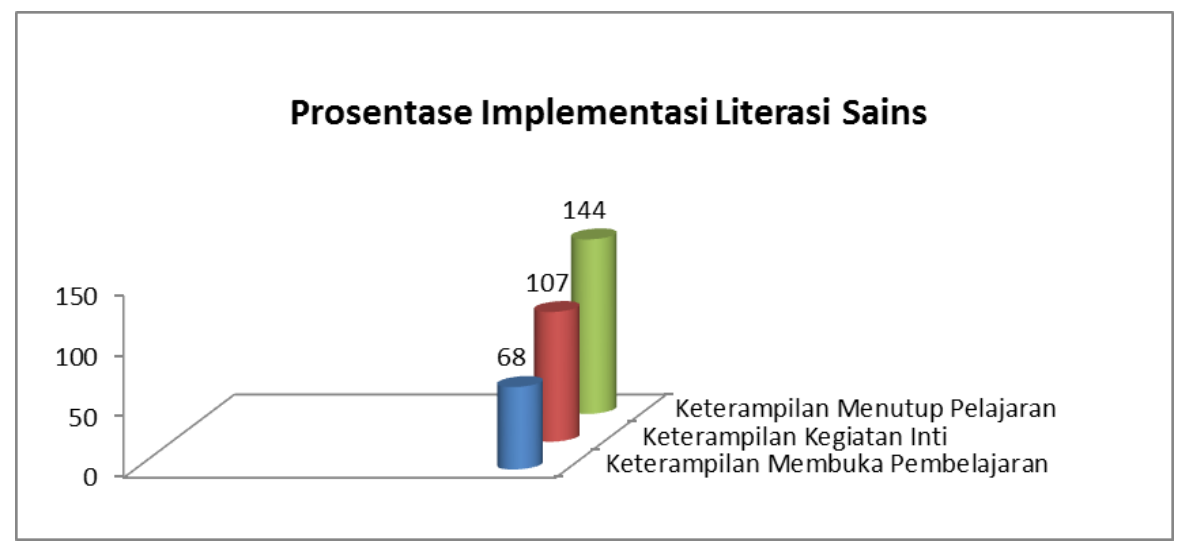

Gambar 1. Implementasi Literasi Sains 
Berdasarkan penilaian implementasi literasi sains dalam pembelajaran maka pada kegiatan membuka pembelajaran naik menjadi 144\%, keterampilan dalam kegiatan inti sebesar 107\% dan keterampilan dalam membuka pembelajaran meningkat menjadi 68\%. Hal ini menunjukkan bahwa guruguru sudah menggunakan literasi sains dalam mengajar, terlihat pada saat mengajar mereka sudah memberikan contoh-contoh yang nyata dan kontekstual. Kemudian mereka juga sudah berfokus kepada meningkatkan keterlibatan siswa dalam pembelajaran dan teacher centered sudah mulai ditinggalkan. Sehingga dapat dikatakan guru-guru sebagian besar telah baik mengimplementasikan literasi sains dalam pembelajarannya.

Pada kegiatan akhir program abdimas dilakukan kegiatan pengukuran dan evaluasi program. Evaluasi dilakukan secara bertahap, peningkatan kemampuan berpikir kritis siswa dengan penerapan literasi sains dengan pembelajaran inkuiri. Hasil selanjutnya dikomunikasikan bersama dengan para guru di sekolah mitra. Kegiatan pengukuran dilakukan dengan menggunakan data observasi awal dan observasi akhir. Aspek yang diukur adalah laju peningkatan dari profil awal kemampuan kritis siswa sebelum penerapan pembelajaran inkuiri dan setelah dilakukan pembelajaran inkuiri. Data kemampuan berpikir kritis siswa setelah diterapkan literasi sains dengan pembelajaran inkuiri sebelum dilakukan program abdimas setelah dilakukan kegiatan PKM dideskripsikan melalui tabel berikut ini:

Tabel 2. Profil Kemampuan Berpikir Kritis Siswa dalam Literasi Sains

\begin{tabular}{|c|c|c|c|c|}
\hline \multirow{2}{*}{ SEKOLAH MITRA } & \multirow{2}{*}{$\begin{array}{l}\text { JUMLAH } \\
\text { PESERTA }\end{array}$} & \multicolumn{3}{|c|}{ PENILAIAN KEMAMPUAN BERPIKIR KRITIS SISWA } \\
\hline & & $\mathrm{B}$ & $\mathrm{KB}$ & TB \\
\hline & 25 & & & \\
\hline Profil Awal & & 7 & 12 & 6 \\
\hline Profil Akhir & & 14 & 9 & 2 \\
\hline Peningkatan & & 7 & 3 & 4 \\
\hline$\%$ Peningkatan & & $100 \%$ & $25 \%$ & $67 \%$ \\
\hline
\end{tabular}

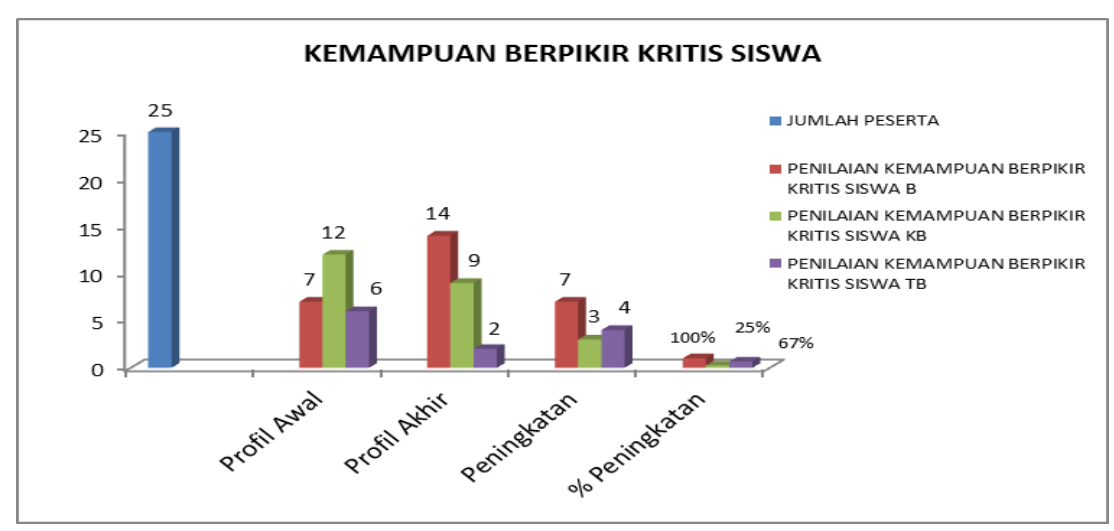

Gambar 2. Grafik Kemampuan Berpikir Siswa

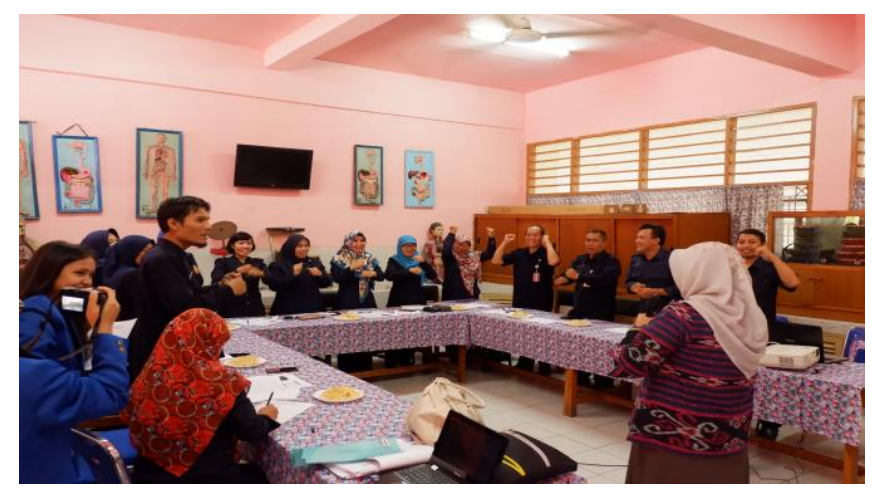

Gambar 3. Kegiatan Sosialisasi Literasi 


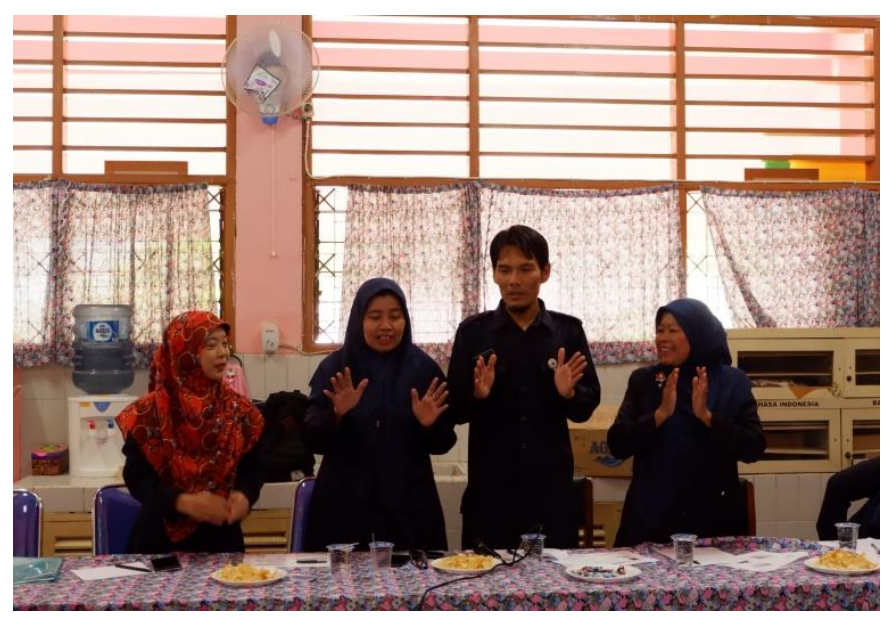

Gambar 4. Kegiatan simulasi kelompok

\section{Simpulan dan saran}

Berdasarkan hasil program kemitraan masyarakat yang telah dilaksanakan, maka dapat disimpulkan bahwa; (1) Adanya dukungan dari sekolah mitra dalam pelaksanaan program abdimas. (2) Adanya peningkatan pemahaman literasi sains dalam pembelajaran baik oleh guru maupun bagi siswanya. Ini berari guru dan siswa sudah mengaplikasikan kegiatan literasi sekolah yang sesuai dengan yang diagendakan oleh pemerintah dan di sekolah itu sendiri.

Adapun saran yang dapat diberikan adalah, pertama Literasi sains perlu dikembangkan secara berkelanjutan dalam pembelajaran dengan cara tetap konsisten dalam merencanakan dan mengaplikasikan dalam pembelajaran di kelas. Kedua siswa selalu diaktifkan kemampuan berpikir kritisnya dengan materi-materi yang kontekstual dengan kehidupan mereka.

\section{Daftar Rujukan}

Ardy, S. (2018, April). Peran Guru dan Gerakan Literasi. Komapas, pp. 1-2.

Hasyim, M. H. M. (2014). Penerapan Fungsi Guru Dalam Proses Pembelajaran. AULADUNA: Jurnal Pendidikan Dasar Islam.

Ibda, H., \& Rahmadi, E. (2018). Penguatan Literasi Baru pada Guru Madrasah Ibtidaiyah dalam Menjawab Tantangan Era Revolusi Industri 4.0. JRTIE: Journal of Research and Thought of Islamic Education, $1(1), 1-21$.

Ismail, M. I. (2010). KINERJA DAN KOMPETENSI GURU DALAM PEMBELAJARAN. Lentera Pendidikan: Jurnal Ilmu Tarbiyah Dan Keguruan. https://doi.org/10.24252/lp.2010v13n1a4

Jufri, A. W., Ramdani, A., Gunawan, G., Bachtiar, I., \& Wildan, W. (2018). Peningkatan Kompetensi Guru IPA Kota Mataram dalam Memfasilitasi Penguasaan Keterampilan Abad Ke 21 Siswa SMP. Jurnal Pengabdian Magister Pendidikan IPA, 1(1). https://doi.org/10.29303/jpmpi.v1i1.207

Kharizmi, M. (2015). Kesulitan siswa sekolah dasar dalam meningkatkan kemampuan literasi. Jurnal Pendidikan Dasar, 2(2), 11-21.

Kurnianingsih, I., Rosini, dan Ismayati, N. (2017). Upaya Peningkatan Kemampuan Literasi Digital bagi Tenaga. Jurnal Pengabdian Kepada Masyarakat, 3(1), 61-76. https://doi.org/10.22146/jpkm.25370

Nurdin, N. (2019). Urgensi Literasi Sains Dalam Meningkatkan Kompetensi Widyaiswara PAI BDK Aceh Di Era Millenial. Jurnal Pendidikan Sains Indonesia, 7(1), 55-63. https://doi.org/10.24815/jpsi.v7i1.12476. 
Nuri Ramadhan. (2017). Tugas, peran kompetensi dan tanggungjawab menjadi guru profesional. Http://semnasfis.unimed.ac.id.

Purwaningtyas, F. (2018). Literasi Informasi dan Literasi Media. Jurnal Iqra' (Vol. 12).

Rosdiana, L., Nurita, T., \& Sabtiawan, W. B. (2018). PENGEMBANGAN LKM UNTUK MENINGKATKAN LITERASI SAINS CALON GURU IPA. Jurnal Penelitian Pendidikan IPA, 3(1), 27. https://doi.org/10.26740/jppipa.v3n1.p27-32.

Seknun, M. Y. (2012). KEDUDUKAN GURU SEBAGAI PENDIDIK. Lentera Pendidikan : Jurnal Ilmu Tarbiyah Dan Keguruan. https://doi.org/10.24252/lp.2012v15n1a10.

Situmorang, R. P. (2016). INTEGRASI LITERASI SAINS PESERTA DIDIK DALAM PEMBELAJARAN SAINS. Satya Widya, 32(1), 49. https://doi.org/10.24246/j.sw.2016.v32.i1.p49-56.

Syofyan, H. H. A. (2016). Penerapan Metode Problem Solving Pada Pembelajaran IPA Untuk Peningkatan Kemampuan Berpikir Kritis Siswa (Penelitian Tindakan Kelas Siswa Kelas V di SDN 3 Kreo Tangerang). ISBN: 978-979-3649-96-2. Prosiding Seminar Nasional Multi Disiplin Ilmu \& Call for Papersunisbank (Sendi_U) Ke-2 Tahun 2016.

Syofyan, H., \& Ismail, I. (2018). PEMBELAJARAN INOVATIF DAN INTERAKTIF DALAM PEMBELAJARAN IPA. QARDHUL HASAN: MEDIA PENGABDIAN KEPADA MASYARAKAT, 4(1), 65. https://doi.org/10.30997/qh.v4i1.1189.

Syofyan, H., MS, Z., \& Sumantri, M. S. (2019). Use of Integrated Thematic Teaching Materials Based on Problem Solving in Natural Science Learning in Elementary Schools. https://doi.org/10.4108/eai.21-11-2018.2282034 